\title{
The effect of processing parameters on the mechanical characteristics of PLA produced by a 3D FFF printer
}

\author{
H. Gonabadi ${ }^{1}$ - A. Yadav ${ }^{1}$ • S. J. Bull ${ }^{1}$ \\ Received: 5 June 2020 / Accepted: 22 September 2020 / Published online: 2 October 2020 \\ (C) The Author(s) 2020
}

\begin{abstract}
3D printing by fused filament fabrication (FFF) provides an innovative manufacturing method for complex geometry components. Since FFF is a layered manufacturing process, effects of process parameters are of concern when plastic materials such as polylactic acid (PLA), polystyrene and nylon are used. This study explores how the process parameters, e.g. build orientation and infill pattern/density, affect the mechanical response of PLA samples produced using FFF. Digital image correlation (DIC) was employed to get full-field surface-strain measurements. The results show the influence of build orientation and infill density is significant. For on-edge orientation, the tensile strength and Young's modulus were $55 \mathrm{MPa}$ and $3.5 \mathrm{GPa}$ respectively, which were about $91 \%$ and $40 \%$ less for the upright orientation, demonstrating a significant anisotropy. The tensile strength and Young's modulus increased with increasing infill density. In contrast, different infill patterns have no significant effect. Considering the influence of build orientation, based on the experimental results, a constitutive model derived from the laminate plate theory was employed. The material parameters were determined by tensile tests. Results demonstrated a reasonable agreement between the experimental data and the predictive model. Similar anisotropy to tension was observed in shear tests; shear modulus and shear strength for $45^{\circ}$ flat orientation were about $1.55 \mathrm{GPa}$ and $36 \mathrm{MPa}$, whereas for upright specimens they were about $0.95 \mathrm{GPa}$ and $18 \mathrm{MPa}$, respectively. The findings provide a framework for systematic mechanical characterisation of 3D-printed polymers and potential ways of choosing process parameters to maximise performance for a given design.
\end{abstract}

Keywords 3D printing $\cdot$ Rapid prototyping $\cdot$ Fused deposition modelling $\cdot$ Digital image correlation $\cdot$ Mechanical characteristics

\section{Introduction}

In comparison with traditional manufacturing methods, 3D printing is a rapid prototyping technology that offers advantages such as reduction of the production cost and material waste, ability to manufacture complex geometries and being less labour-intensive finding new applications in many areas of aerospace [1, 2], construction and civil engineering [3-6] biomedical engineering [7-10] and robotics [11,12].

Among the different techniques for producing polymeric 3D printing parts, fused filament fabrication (FFF) is one of the most developed additive manufacturing processes involving extrusion of a polymeric filament material through a heated nozzle to deposit semi-molten material in a layer by layer

S. J. Bull

steve.bull@newcastle.ac.uk

1 School of Engineering, Newcastle University, Newcastle upon Tyne NE17RU, UK fashion on a substrate until the desired object geometry is produced. In FFF, based on a computer-aided design (CAD) model of the component, a computer programme is used to slice the model into single layers with defined thickness that build up the full geometry of the object. The slice geometry and other machine parameters are the converted into G-code which can be read by the printer to generate the object.

Generally in 3D-printed FFF parts, the existence of filament gaps (voids) between deposited layers, the variation in the layer to layer adhesion quality and the shrinkage during the cooling can all affect the mechanical properties and cause anisotropy [13-15]. It has been also shown that several parameters such as build orientation, layer thickness, raster width and orientation/ extruded fibre layout, infill pattern/density, temperature and feed rate can influence this and have significant impact on the quality of FFF parts in terms of mechanical properties [14, 16-25]. Therefore, a number of input conditions and process variables need to be optimised in order to generate high-quality components. This necessitates a better understanding of the processproperties relationship of 3D FFF parts. 
Limited knowledge about the inherently heterogeneous mechanical behaviour of 3D FFF-fabricated materials and lack of suitable design tools is a major barrier of using this technology for producing functional parts. Mechanical properties of FFF-fabricated parts are a key measure of their quality and performance. For example, the orthotropic elastic constants and strength parameters are required in the design process of highly stressed 3D-printed structures. Therefore, to drive further application of 3D printing technology and address the issues related to the anisotropy of the mechanical properties of these parts (structural integrity), much research has been done in order to establish an experimental relationship between process variables and mechanical properties of 3D FFF-fabricated parts. To date, no complete and comprehensive study exists for any material but considerable information is available for some aspects.

The effects of build orientation on mechanical behaviour of FFF parts have been studied [14, 20, 21, 26-28] and it has been found that the highest mechanical properties are obtained when the filament deposition direction coincides with the tensile load direction, however, a wide range of build orientations with respect to the tensile direction have not been investigated previously. In addition, the effect of layer height and raster orientation on the tensile properties of 3D-printed polylactic acid (PLA) and acrylonitrile butadiene styrene (ABS) parts have been investigated by a number of workers [17, 29-32], and it has been found that increasing raster angle towards $90^{\circ}$ reduces the tensile strength, while a lower value of layer height results in higher tensile strength. To account for the effect of layer thickness and air gap, it has been found that negative air gap and minimum layer thickness can improve the mechanical properties of ABS-printed parts [21, 31, 33]. Also, the effect of build orientation, layer thickness and feed rate on the mechanical properties of PLA parts have been investigated by [34], and it has been shown that the best mechanical properties are obtained for samples printed on edge or flat orientations with the lowest value of layer thickness. In terms of analytical study, classical laminate theory (CLT) has been used to estimate the effect of raster angle on tensile properties of 3D-printed samples [20]. In this work, the values of longitudinal and transverse modulus, the shear modulus and Poisson's ratio required to calculate the stiffness matrix have been determined experimentally from the horizontally built specimens. The present study shows that using the experimentally calculated parameters of elastic constants of the upright 3D-printed samples in the stiffness matrix, the CLT can also be used to predict the effect of build orientation on the tensile properties. In addition to the use of CLT, the use of numerical homogenisation technique based on Finite Element (FE) modelling of Representative Volume Element (RVE) has been found useful to predict the mechanical behaviour of 3Dprinted parts as a function of both build and raster orientation; however, the results of this study is not comparable with experiment as the bonding between the adjacent filaments was assumed to be perfect in the FE model of RVE, whereas it is not the case in printed samples [35].

While the printing orientation and infill density can alter tensile, flexural and compressive properties [36-38], many of these studies has only been done with ABS, and only relatively recently PLA has been the topic of such investigations. Due to the advantages of PLA (biocompatibility and environmentally friendly material) and the fact that many desktop printers nowadays use PLA as it is easier to print without curling, this paper focuses on the effect of FFF process parameters on PLA parts. Although some mechanical properties of PLA have been investigated recently, there is little information about the evaluation of shear properties. In addition, the majority of the previous research is focused on the study of raster angle and build orientation on the tensile properties of 3D-printed parts, with less attention on the effect of infill pattern and infill density. Given the importance of orthotropic elastic constants (which are obtained from standard tension and shear tests) in the design process of load-bearing 3D-printed structures, it is necessary to understand the effect of infill density, infill pattern and build orientation on the tensile and shear properties of 3D-printed PLA parts.

Although, many studies have sought to improve the load bearing capacity of parts manufactured using FFF by optimising various printing parameters [39-43], the lack of standard method to assess the failure progression and to measure the components of engineering strains during mechanical deformation has resulted in inconsistent results indicating that the influence of printing conditions on mechanical properties still needs to be further investigated. In fact, most studies on the mechanical response of 3D FFF parts are based on using conventional strain gauges and extensometer to build the stress-strain curve and extract the main parameters such as Young's modulus, failure strain and ultimate/yield strength while lacking other properties such as Poisson's ratio and longitudinal, transverse and shear data which are essential for fully characterising their mechanical performance. In addition, in FFF parts, the irregularity of the geometric features associated with filament-scale structure can change the local behaviour of the printed parts under the deformation leading to non-uniform distribution of strain; this is why a unique technique to map the strain distribution is also required.

Due to the anisotropy effect of 3D-printed parts, using conventional strain gauges does not reveal actual information about strain localisation and the gradient of strain fields. An ideal technique for measuring strain and tracking the failure progression in 3D FFF-fabricated parts is a non-contact strain measurement method such as digital image correlation (DIC). Using DIC, restrictions regarding specimen dimensions to obtain a uniform displacement distribution can be eliminated. Full-field measurement digital image processing techniques, such as DIC, were introduced in the field of 3D-printed 
materials to map the strain fields and to measure components of strains and Poisson's ratio [23, 24, 44, 45]. However, to date, the determination of mesoscopic deformation of heterogeneous 3D FFF parts and the influence of material structure heterogeneity on both tensile and shear strain have not been widely investigated by this technique.

In order to bring the FFF technology into volume production for producing functional parts, the optimising of $3 \mathrm{D}$ printing parameters to produce suitable mechanical properties needs to be investigated thoroughly. This study aims to look at the effect of parameters such as build orientation and infill density/pattern on the tensile and shear properties of 3Dprinted parts with the aid of a DIC system. DIC is also used to assess the difference observed in the strain/deformation fields of these materials under tensile and shear loads for the same process parameters. Moreover, full-field DIC strain maps are used to show the areas on the specimen surface where damage occurs. A better understanding of mechanical performance, surface-strain fields and failure progression of 3D FFF parts under deformation will make the use of these parts more reliable and increase the design safety of engineering parts manufactured by them.

\section{Orthotropic constitutive model}

In the FFF process, the materials are manufactured by stacking layers deposited from the filament by a rastering process (see in Fig. 1). As a result, each layer can be considered as a lamina (ply). In this study an orthotropic model which is well-known in the composite field is used to evaluate the effect of build orientation on mechanical behaviour of 3D FFF tension test coupons, and a comparison between analytical and experimental solutions can be made to validate the results.

Given the plane stress condition (thickness dimension is much smaller than the length and width dimensions [46]), in 3D FFF tension specimens, only the values of in-plane engineering constants (longitudinal modulus, in-plane transverse modulus, in-plane shear modulus, major and minor Poisson's ratio) are required to define the orthotropic nature of the lamina. These values are calculated experimentally from tensile tests in the longitudinal $\left(0^{\circ}\right.$ on-edge sample) and transverse (upright sample) directions (Fig. 6) as well as the Iosipescu shear test (Table 7). Therefore, the equations used in the stress analysis of tensile samples are applied to the plane stress condition and the constitutive equation which relates the stress to strain is defined as follows:

$$
\left[\begin{array}{c}
\sigma_{1} \\
\sigma_{2} \\
\sigma_{12}
\end{array}\right]=\left[Q_{i j}\right]\left[\begin{array}{c}
\varepsilon_{1} \\
\varepsilon_{2} \\
\gamma_{12}
\end{array}\right] \text { where }\left[Q_{i j}\right]=\left[\begin{array}{ccc}
Q_{11}=\frac{E_{1}}{1-\nu_{12} \nu_{21}} & Q_{12}=\frac{\nu_{21} E_{1}}{1-\nu_{12} \nu_{21}} & Q_{16}=0 \\
Q_{21}=\frac{\nu_{12} E_{1}}{1-\nu_{12} \nu_{21}} & Q_{22}=\frac{E_{2}}{1-\nu_{12} \nu_{21}} & Q_{26}=0 \\
Q_{61}=0 & Q_{62}=0 & Q_{66}=G_{12}
\end{array}\right]
$$

where $\sigma_{1}, \sigma_{2}$ and $\sigma_{12}$ are the longitudinal (parallel to the filament), in-plane transverse (perpendicular to the filament) and in-plane shear stresses respectively. Correspondingly, $\varepsilon_{1}$, $\varepsilon_{2}$ and $\gamma_{12}$ represent the in-plane engineering strains. $E_{1}$ is the elastic modulus of the $0^{\circ}$ on-edge sample, $E_{2}$ is the elastic modulus of the upright sample, $G_{12}$ is the in-plane shear modulus of the $0^{\circ}$ on-edge sample, and $\nu_{12}$ and $\nu_{21}$ denote the major and minor Poisson's ratios respectively. In this study, analytical solutions developed for tension testing of 3D FFF parts are then validated with experimentally generated data. For laminated 3D FFF parts subjected to a pure uniaxial tension load of $P$ [46], the in-plane stresses for each layer:

$$
\left[\begin{array}{c}
\sigma_{1} \\
\sigma_{2} \\
\sigma_{12}
\end{array}\right]=\left[Q_{i j}\right]\left[A_{i j}\right]^{-1}\left[\begin{array}{c}
P / b \\
0 \\
0
\end{array}\right] \text { where }\left[A_{i j}\right]=\sum_{k=1}^{n}\left[Q_{i j}\right]
$$

where $P$ is the tension load, $t$ is the thickness, $n$ is the number of layers through the thickness direction of the laminate, $b$ is the width of specimen and the matrix $\left[A_{i j}\right]^{-1}$ is the inverted extensional stiffness matrix $\left[A_{i j}\right]$ showing the relationship between components of stress and strain [46]. It must be noted that in the above equations, the loading direction is either parallel or perpendicular to the filament direction; when the loading direction does not correspond to the principal material directions (given the relation between the principal and material coordinate system (Fig. 2) where coupling between extension and shear occurs), the stiffness matrix $\left(\left[Q_{i j}\right]\right)$ is calculated using free-body diagrams. Full descriptions of the equations are detailed in [46].
Fig. 1 a FFF-processed materials. b Lamina structure with the material coordinate system $\left(x_{1}, x_{2}, x_{3}\right)$ (a)

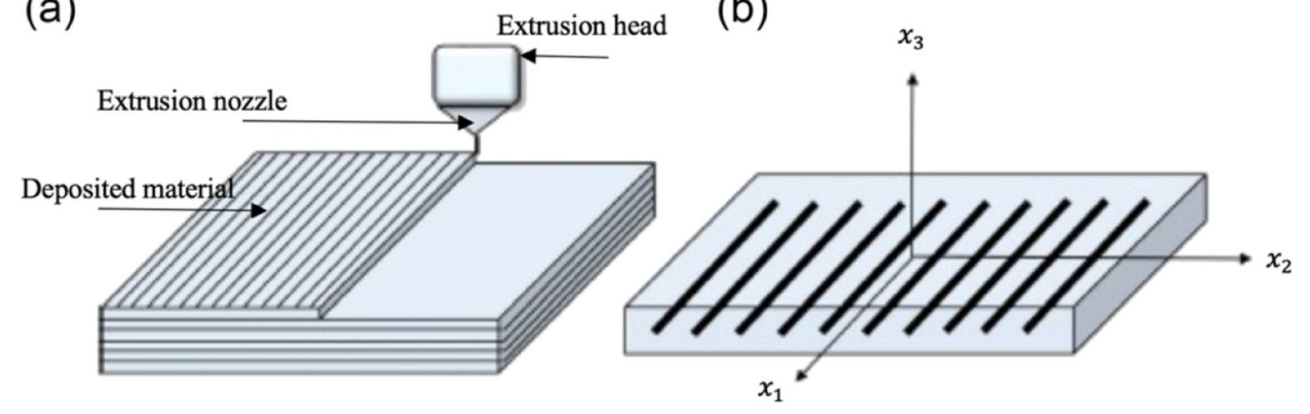




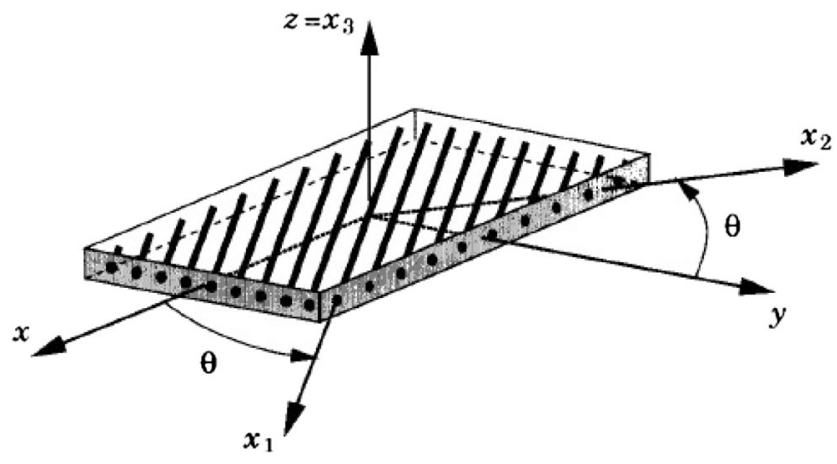

Fig. 2 A lamina with material $\left(x_{1}, x_{2}, x_{3}\right)$ and principal $(x, y, z)$ coordinate system

\section{Methods}

\subsection{Sample preparation}

All specimens were produced using a low cost fused filament fabrication (FFF) 3D printer (Creality Ender-3, Shenzhen, China). A polylactic acid (PLA) filament from the same manufacturer was used to obtain the 3D-printed specimens. The main advantage of PLA is that it is easy to use, provides dependable design, adheres well and does not suffer from any substantial distortion during printing. The Ultimaker Cura 4.0 edition was used as the slicer to generate the machine code for the $3 \mathrm{D} \mathrm{FFF}$ printer from the 3D model file. Simple 3D-printed test sample designs based on ASTM standards were used in all cases. The PLA filament's initial diameter was $1.75 \mathrm{~mm}$ with a nozzle of diameter $0.4 \mathrm{~mm}$. The extrusion and bed temperatures were maintained at $200{ }^{\circ} \mathrm{C}$ and $60^{\circ} \mathrm{C}$ respectively. Once the first layer is deposited on the heated bed, the head lifts and proceeds to deposit the following layers with fan cooling; this approach promotes adhesion. The process parameters like raster width, raster starting angle and temperature were software default values for the printer. Tensile and shear test specimens were manufactured with dog-bone and Iosipescu specimen geometry respectively (Table 1 and 2).

The specimens were prepared with four infill densities of different percentages $(25 \%, 50 \%, 75 \%$ and $100 \%)$, eight different build orientations $\left(0^{\circ}, 15^{\circ}, 30^{\circ}, 45^{\circ}, 60^{\circ}, 75^{\circ}, 90^{\circ}\right.$, flat $0^{\circ}$ and upright (see Fig. 3b, c) and four different infill patterns (square, triangle, concentric and gyroid) to evaluate the effect on mechanical properties. The manufacturing parameters for tensile and shear test samples are presented in Table 3 .
For all upright and on-edge samples, a raft of PLA was deposited prior to sample manufacture to ensure adhesion. For the upright samples between $15^{\circ}$ and $75^{\circ}$ and the onedge samples, a support was used to ensure the geometry was maintained. The raft and support parameters were set by the CURA software as the default for the chosen printer.

The measured density of the PLA filament was $1.22 \pm$ $0.02 \mathrm{~g} / \mathrm{cm}^{3}$ in line with the expected literature value and the manufacturer's data sheet. The average sample density varied between 56 and $99 \%$ of this value as infill density increased. The sample structure has a relatively dense shell surrounding the region of reduced infill density - thus, the average density of the sample will depend on sample size, shape and shell thickness as well as build orientation. In this study, about $42 \%$ of the sample volume was shell and the rest infill.

\subsection{Mechanical testing}

The tensile and shear testing of 3D-printed specimens and the tensile testing on of PLA filament were carried out using a Tinius Olsen Universal testing machine fitted with a $10 \mathrm{kN}$ load cell with $\pm 0.5 \%$ accuracy. These mechanical tests were conducted in conjunction with digital image correlation (Fig. 4). Before any 3D FFF printing, tensile testing on the PLA filament was carried out to provide baseline data. PLA specimens of $1.72 \mathrm{~mm}$ in diameter (nominally $1.75 \mathrm{~mm}$ ) and $200 \mathrm{~mm}$ in length were clamped inside the load frame on the Tinius Olsen Universal machine using capstan grips. The geometry of specimens for subsequent tension and shear tests were set according to ASTM D638 [47] and ASTM D5379 respectively [48, 49]. A schematic view of the geometry of specimens is illustrated in Fig. 3d, e. The specifications of all specimens are mentioned in Table 3.

Before testing, the specimens were air dried at a temperature of $50{ }^{\circ} \mathrm{C}$. The tensile tests were performed using type IV dog-bone-shaped specimens with a thickness of $2 \mathrm{~mm}$ and a width of $6 \mathrm{~mm}$ (Table 1), and shear tests were performed using the Iosipescu specimen (Table 2). The test speed was $2 \mathrm{~mm} /$ min. All tests were conducted under ambient conditions (about $22{ }^{\circ} \mathrm{C}$ and $60 \%$ humidity). At least five specimens of each condition were tested. During the mechanical tests, the DIC system was used for full-field strain measurement.

Table 1 Geometry of the tensile test specimen

\begin{tabular}{llllll}
\hline Type & Gauge length & $\begin{array}{l}\text { Width at } \\
\text { gauge length }\end{array}$ & Thickness & $\begin{array}{l}\text { Distance } \\
\text { between grips }\end{array}$ & Width at grips \\
\hline $\begin{array}{l}\text { Tension } \\
\text { (dog bone) }\end{array}$ & $35 \mathrm{~mm}$ & $6 \mathrm{~mm}$ & $2 \mathrm{~mm}$ & $70 \mathrm{~mm}$ & $20 \mathrm{~mm}$ \\
\hline
\end{tabular}


Table 2 Geometry of the shear test specimen

\begin{tabular}{lllllll}
\hline Type & $\begin{array}{l}\text { Distance between } \\
\text { notches }\end{array}$ & $\begin{array}{l}\text { Depth of } \\
\text { notches }\end{array}$ & $\begin{array}{l}\text { Radius of end } \\
\text { notches }\end{array}$ & Thickness & Width & Length \\
\hline Iosipescu & $11.4 \mathrm{~mm}$ & $3.8 \mathrm{~mm}$ & $1.3 \mathrm{~mm}$ & $5 \mathrm{~mm}$ & $19 \mathrm{~mm}$ & $76 \mathrm{~mm}$ \\
\hline
\end{tabular}

\subsection{Digital image correlation (DIC) testing}

Full-field deformation measurements were carried out using the DIC technique. DIC is based on the comparison between two images acquired before and after the deformation. A CCD camera was used for image acquisition; these images are digitised and analysed to create strain maps [50, 51]. Before measurement, specimens were sprayed alternately using black and white paint to create a speckle pattern with sufficient greyscale contrast for analysis. The camera features a spatial resolution of $5.5 \mu \mathrm{m} / \mathrm{pixel}$ and is equipped with lenses of 0.193 magnification at the working distance of about $300 \mathrm{~mm}$. An external cold light source was used to illuminate the whole sample uniformly for minimum errors introduced by variable lightning conditions; this is essential for strain mapping. Image acquisition was synchronised with the beginning of each mechanical test. Digital image correlation (DIC) allows a full-field strain measurement of the surface using a speckle pattern distribution [50]. The images were recorded during the tensile test using the Imetrum video-gauge software at a rate of $5 \mathrm{~Hz}$, and the images obtained were then processed with the VIC-2D software from Correlated Solutions, Inc. The software was used to interpolate the points and give the fullfield strain maps and stress-strain curves for the 3D-printed specimens.

\section{Results and discussion}

\subsection{Tensile tests}

All of the investigations in this study were performed using an amorphous polylactic acid (PLA) filament, which is extensively used in 3D FFF technology, as PLA has low a melting point and is environmentally greener [52]. The average elastic modulus, tensile strength and the failure strain of the PLA filament were found to be about $3.5 \pm 0.1 \mathrm{GPa}, 51 \pm 1 \mathrm{MPa}$ and $6 \pm 0.5 \%$, respectively. Similar properties for PLA filament have been reported in the literature [53]. The 3D FFF printer instrument controls both the direction of the layer orientation as well as the extruded fibre raster pattern. Past research was primarily concerned with the variation of mechanical properties with build orientation, while infill pattern and infill density have rarely been assessed. To give better insight into the mechanical response of the material, a systematic study of factors affecting performance has been undertaken here.

\subsubsection{Effect of build orientation on mechanical properties}

Tensile tests were conducted on 3D-printed samples with different build orientation. Following the recommendation of ASTM standard D-638, for each building orientation, 5 (a)

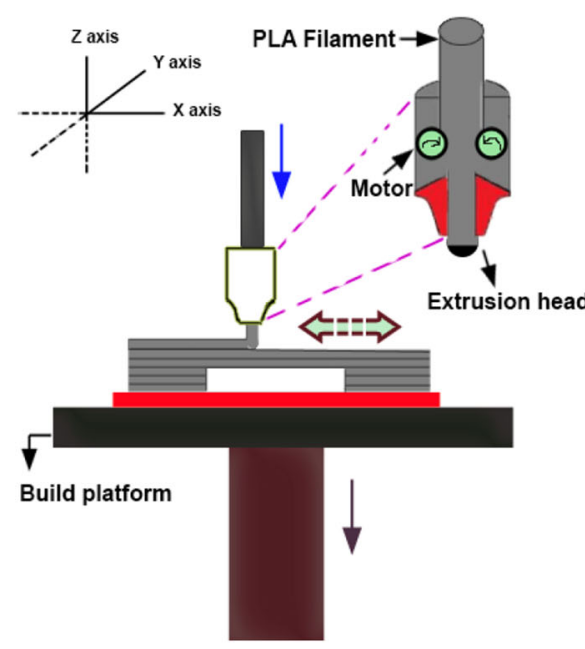

Schematic illustration of fused filament fabrication (FFF) (b)

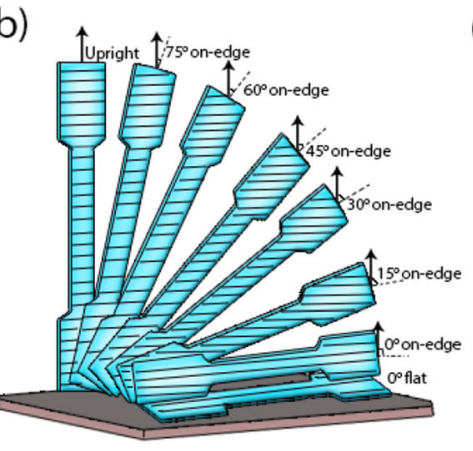

(d)

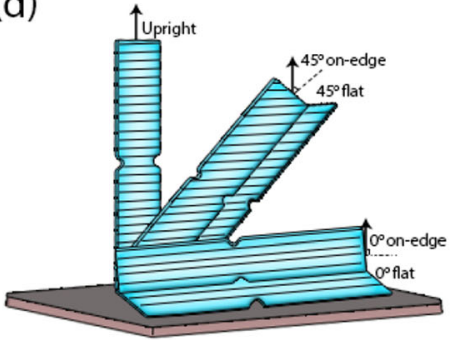

(c)

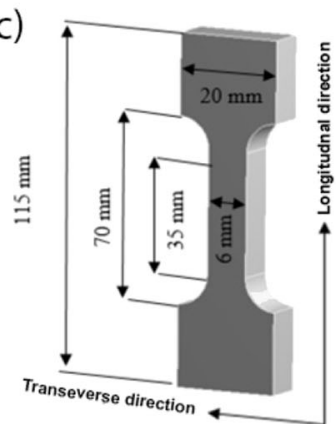

(e)

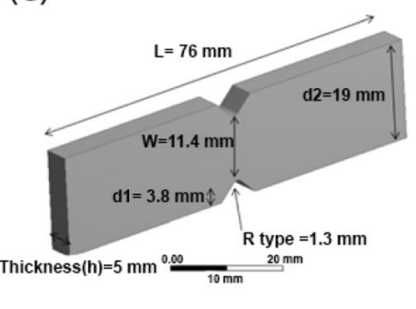

Fig. 3 a Schematic view of 3D FFF printer, where the model is built layer by layer. b Schematic of the orientations of the specimens used in this investigation for tension, $\mathbf{c}$ the orientations of the specimens used in this investigation for shear, $\mathbf{d}$ tensile specimen, and $\mathbf{e}$ Iosipescu shear specimen 
Table 3 Process parameter of 3D-printed parts used for tensile and shear tests

\begin{tabular}{|c|c|c|c|c|c|c|c|c|c|}
\hline \multirow{2}{*}{$\frac{\text { Parameter }}{\text { Infill density (\%) }}$} & \multirow{2}{*}{$\begin{array}{c}\text { Method } \\
\text { Tension }\end{array}$} & \multicolumn{8}{|c|}{ Description } \\
\hline & & 25 & & 50 & 75 & & 100 & & \\
\hline & Shear & - & & & & & & & \\
\hline \multirow[t]{2}{*}{ Manufacturing orientation } & Tension & $0^{\circ}$ & $15^{\circ}$ & $30^{\circ}$ & $45^{\circ}$ & $60^{\circ}$ & $75^{\circ}$ & $0^{\circ}$ flat & Upright \\
\hline & Shear & & -edge & $45^{\circ}$ & & $0^{\circ} \mathrm{f}$ & & Upright & \\
\hline \multirow[t]{2}{*}{ Infill pattern } & Tension & squ & & \multirow{2}{*}{\multicolumn{2}{|c|}{ triangle }} & con & tric & gyroid & \\
\hline & Shear & squ & & & & & & & \\
\hline Layer height (mm) & $\begin{array}{l}\text { Tension } \\
\text { Shear }\end{array}$ & \multicolumn{4}{|c|}{0.15} & & & & \\
\hline Shell thickness (mm) & $\begin{array}{l}\text { Tension } \\
\text { Shear }\end{array}$ & \multicolumn{4}{|c|}{1.20} & & & & \\
\hline Nozzle size (mm) & $\begin{array}{l}\text { Tension } \\
\text { Shear }\end{array}$ & \multicolumn{4}{|c|}{0.4} & & & & \\
\hline extrusion temperature $\left({ }^{\circ} \mathrm{C}\right)$ & $\begin{array}{l}\text { Tension } \\
\text { Shear }\end{array}$ & \multicolumn{4}{|c|}{220} & & & & \\
\hline Bed temperature $\left({ }^{\circ} \mathrm{C}\right)$ & $\begin{array}{l}\text { Tension } \\
\text { Shear }\end{array}$ & \multicolumn{4}{|c|}{60} & & & & \\
\hline Deposition speed $(\mathrm{mm} / \mathrm{s})$ & $\begin{array}{l}\text { Tension } \\
\text { Shear }\end{array}$ & \multicolumn{4}{|l|}{60} & & & & \\
\hline
\end{tabular}

specimens were tested. In terms of failure location and depending on the failure modes (i.e. inter-layer and intra-layer fracture), for each building orientation, the majority of specimens failed within the gauge length; however, occasionally, some samples failed outside the gauge length. In these cases, the test specimens were 3D-printed again and tensile test was repeated until a successful result was produced.

Figure 5 illustrates stress-strain curves for all the build orientations, as described in the schematic Fig. 3b. There appears to be significant variation in tensile strength, elastic modulus, Poisson's ratio and elongation as a function of build orientation; Fig. 6 summarises the mechanical test results revealing that the PLA exhibits remarkable variation with build orientation.

The on-edge build orientation shows highest values of ultimate tensile strength and elastic modulus, which were about $\sigma_{\mathrm{UTS}}=55 \mathrm{MPa}$ and $E_{y}=3.5 \mathrm{GPa}$ respectively. The upright orientation resulted in the lowest values measured here; the tensile strength and elastic modulus were about $\sigma_{\mathrm{UTS}}=5 \mathrm{MPa}$ and $E_{y}=2 \mathrm{GPa}$ respectively. The on-edge orientation showed the highest value for the elongation and Poisson's ratio with an average of about $\varepsilon_{\max }=5 \%$ and $\nu_{m}=0.35$, respectively, higher than the flat $\left(\varepsilon_{\max }=2.5 \%\right.$ and $\left.\nu_{m}=0.32\right)$ and upright ( $\varepsilon_{\max }=0.45 \%$ and $\nu_{m}=0.2$ ) orientations. This indicates that
Fig. 4 Experimental set up for DIC testing a under tensile loading and $\mathbf{b}$ under shear loading (a)

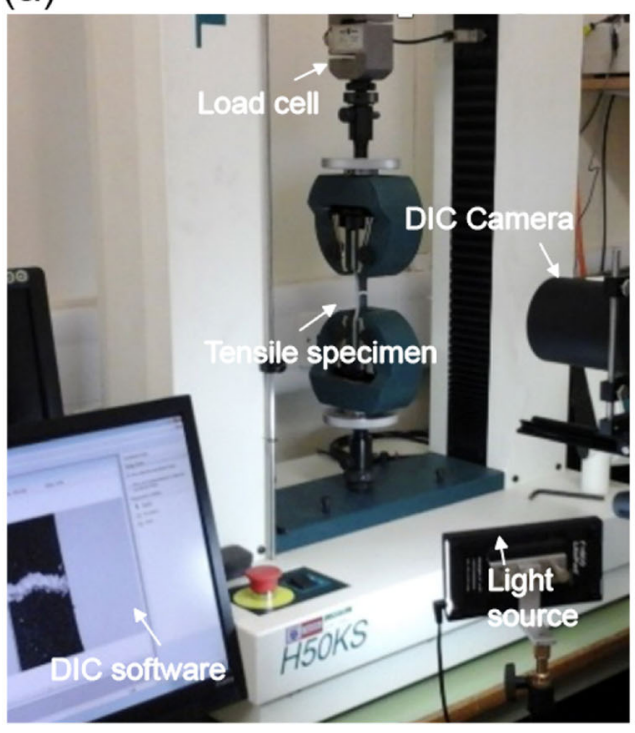

(b)

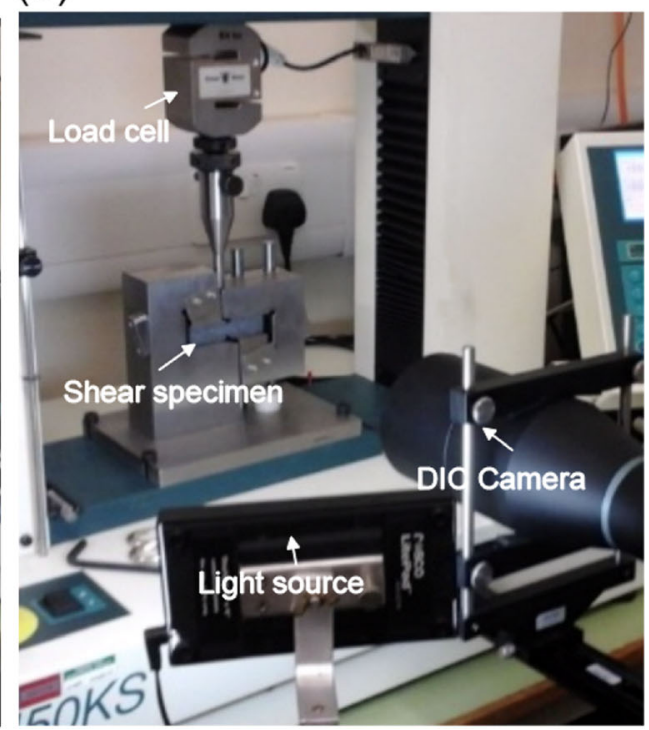


Fig. 5 a Tensile stress-strain curves for different build orientation of 3D FFF-printed PLA measured by DIC method. An infill pattern of parallel fibres in the long dimension of the sample with an infill density of $100 \%$ has been used for 3D printing of these samples. DIC strain distribution map in terms of longitudinal strains prior to the fracture point for different build orientation of 3D FFF-printed tensile specimen of $\mathbf{b} 0^{\circ}$ flat, $\mathbf{c} 0^{\circ}$ on edge, $\mathbf{d} 15^{\circ}$ on edge, e $30^{\circ}$ on edge, $\mathbf{f} 45^{\circ}, \mathbf{g} 60^{\circ}$ on edge, $\mathbf{h} 75^{\circ}$ on edge and $\mathbf{i}$ upright orientation

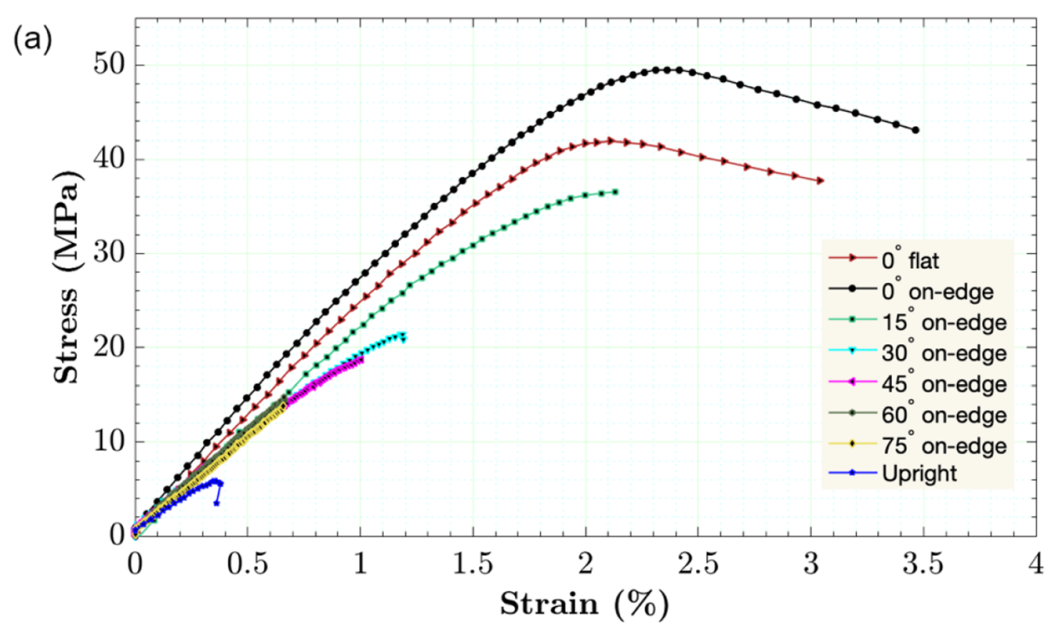

(b)

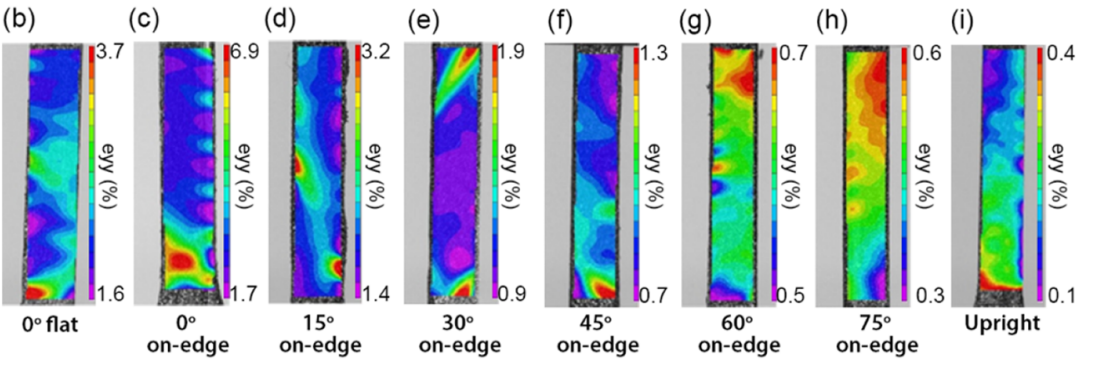

the on-edge orientation has a significant improvement in mechanical properties compared to the other build orientations. When the angle of the on-edge orientation increased from $15^{\circ}$ to $75^{\circ}$, the tensile strength, elastic modulus, Poisson's ratio and elongation decreased (Fig. 6). These results have confirmed observations in previous studies [24, 33].

Figure $5 \mathrm{~b}-\mathrm{i}$ show DIC results in terms of engineering strain plots $\varepsilon_{y y}$ (loading direction) just prior to failure (about
$95 \%$ of failure strain) for the eight different build orientations. All specimens failed within the gauge length. In almost all the cases, the results show a very high localised strain at the edge near to the grip. For the flat build orientation, the high strain concentration occurred at the edge and splitting at the surface was observed. From the DIC images, it can be seen that the highest localised $\varepsilon_{y y}$ strain is aligned perpendicular to the layer direction, with high strain values recorded $\left(\varepsilon_{y y}=3.7 \%\right)$. For

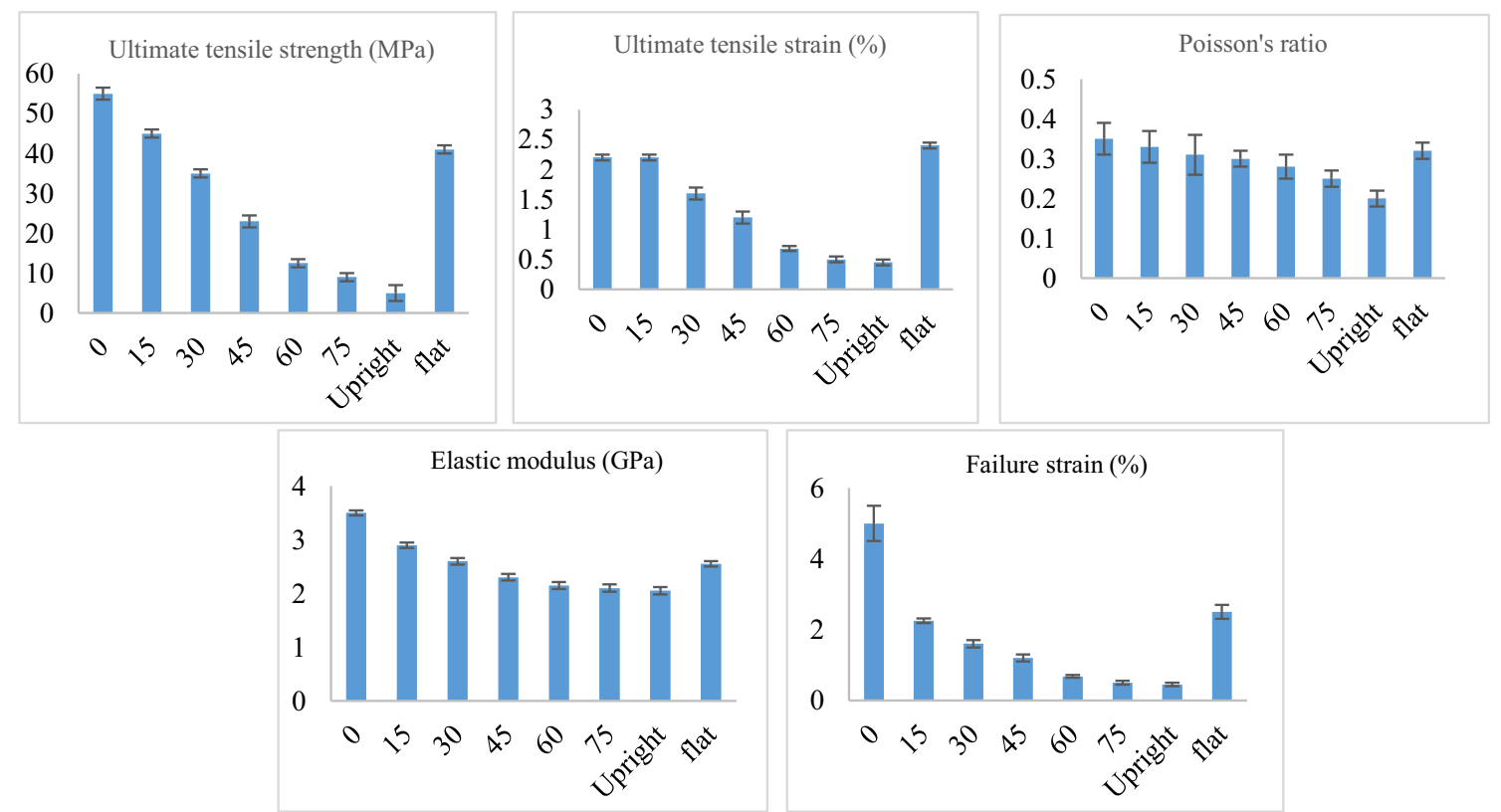

Fig. 6 Tensile properties of 3D FFF-printed PLA as a function of build orientation 
Table 4 Comparison between the yield strength of 3D-printed tension test coupons obtained by experimental and analytical solution

\begin{tabular}{llllll}
\hline Method of measurement & $15^{\circ}$ edge & $30^{\circ}$ edge & $45^{\circ}$ edge & $60^{\circ}$ edge & $75^{\circ}$ edge \\
\hline Experimental (MPa) & $45 \pm 1$ & $35 \pm 2$ & $23 \pm 2$ & $12.5 \pm 0.5$ & $9 \pm 1$ \\
Analytical (MPa) & 44 & 35 & 22 & 12 & 9 \\
Difference (\%) & 2.3 & 0.5 & 4 & 4 & 1 \\
\hline
\end{tabular}

the on-edge orientation, a similar high strain concentration occurred at the edge of the sample. In this case, localised $\varepsilon_{y y}$ strain runs perpendicular to the layer direction, with slightly higher strain values $\left(\varepsilon_{y y}=6.9 \%\right)$ than for the flat orientation. In contrast, for the upright orientation, the highest strain concentration occurred at the edge, and the localised $\varepsilon_{y y}$ strain runs along the layer direction, with relatively low strain values $\left(\varepsilon_{y y}=0.4 \%\right)$; through-layer failure would be expected at this strain level. The $\varepsilon_{y y}$ values with build orientation at $0^{\circ}$ on-edge $\left(\varepsilon_{y y}=6.9 \%\right)$ is considerably higher than build orientation at $75^{\circ}$ on-edge $\left(\varepsilon_{y y}=0.6 \%\right)$, and the noticeably high strain concentration is rotated in conjunction with the build orientation angles further demonstrating the anisotropic behaviour of $3 \mathrm{D}$ FFF parts.

The difference in failure mode can be attributed to two main factors during the 3D FFF manufacturing process: inter-layer and trans-layer failures $[17,21,33,54,55]$. In the case of the upright orientation, the specimens were pulled parallel to the layer deposition plane and load was applied perpendicular to the filament deposition direction, resulting in inter-layer bond failure known as brittle delamination [21, 33]. Due to the limited extent of fusion and hence weak adhesion, a lower tensile strength than that of the individual layer is expected [17, 21, 33, 54, 55]. In contrast, for the on-edge and flat orientations, the layers' deposition direction was perpendicular to the specimen long dimension and the load was applied parallel to the layers, resulting in through-thickness failure for each layer pulled along the longitudinal axis [17, $21,33,54,55]$. This leads to higher tensile strength of the onedge and flat orientations when compared to the upright orientation. The stress-strain curve for the upright orientation indicates brittle behaviour, whereas the on-edge and flat orientations show more ductile behaviour with significant plastic deformation, especially in the case of the on-edge orientation. The on-edge sample with $0^{\circ}$ orientation shows the maximum value of yield stress and tensile strength at failure. This is because of the mechanism described earlier where more layers are loaded longitudinally. Additionally, it is observed that for the build orientation at different angles $\left(15^{\circ}, 30^{\circ}, 45^{\circ}, 60^{\circ}\right.$ and $75^{\circ}$ ), the deformation shows a similar ductile behaviour and plastic deformation, with a considerable anisotropy effect; as the build orientation decreases, the maximum tensile strength also decreases. The main objective of changing the angle of build orientation was to examine the variation of stress/strain behaviour and if it could be further explained using a simple constitutive model.

The yield strength of 3D-printed tension samples was calculated using Eq. 2 (based on the tension load at the yield point) and compared with experimental results in Table 4 indicating that the constitutive model can approximately predict the effect of manufacturing orientation on the yield strength of 3D-printed tension samples. In fact, the measured values are usually about $5 \%$ less than the predicted values regardless of orientation due to the defects introduced into the material during the additive layer manufacturing process.

\subsubsection{Effect of infill density on mechanical properties}

Figure 7 illustrates stress-strain curves for four different infill densities $(25 \%, 50 \%, 75 \%$ and $100 \%)$ with build orientation of $0^{\circ}$ flat. The tensile properties of these samples are provided in Table 5; it can be seen that infill density has a considerable effect on mechanical properties. The tensile strength and Young's modulus increase with infill density (Fig. 8). This observation is consistent with previous studies [56-58]. The justification is that with the increase of the fill density, the volume of air gaps decreases (i.e. an increase in the polymer content of the material) and the number of filament junctions increases which improves the inter-layer bonding strength of the FFF-printed material. Thus, the 3D-printed part can support a higher load. According to Gibson and Ashby [59], relative Young's modulus of a porous material compared to

Table 5 Tensile properties of 3D FFF-printed PLA as a function of infill density

\begin{tabular}{lllllr}
\hline Infill density & $\begin{array}{l}\text { Ultimate tensile } \\
\text { strength (MPa) }\end{array}$ & $\begin{array}{l}\text { Difference } \\
\text { to filament }(\%)\end{array}$ & $\begin{array}{l}\text { Ultimate tensile } \\
\text { strain (\%) }\end{array}$ & $\begin{array}{c}\text { Poisson's ratio } \\
\text { Failure strain (\%) } \\
\text { modulus (GPa) }\end{array}$ \\
\hline $25 \%$ & $29 \pm 1$ & -43 & $2.15 \pm 0.04$ & $0.31 \pm 0.03$ & $2.05 \pm 0.05$ \\
$50 \%$ & $30 \pm 2$ & -41 & $2.15 \pm 0.04$ & $0.32 \pm 0.02$ & $2.15 \pm 0.05$ \\
$75 \%$ & $36 \pm 0.5$ & -29 & $2.5 \pm 0.05$ & $0.32 \pm 0.02$ & $2.5 \pm 0.05$ \\
$100 \%$ & $38 \pm 3$ & -25 & $2.6 \pm 0.05$ & $0.33 \pm 0.01$ & $2.85 \pm 0.15$ \\
\hline
\end{tabular}


Fig. 7 a Tensile stress-strain curves for different infill density of 3D FFF-printed PLA (grid infill pattern with $\pm 45^{\circ}$ wall orientation to the longitudinal axis) measured by the DIC method. DIC strain distribution map along the tensile specimens of different infill density of $\mathbf{b}$ $25 \%$, c $50 \%$, d $75 \%$ and e $100 \%$

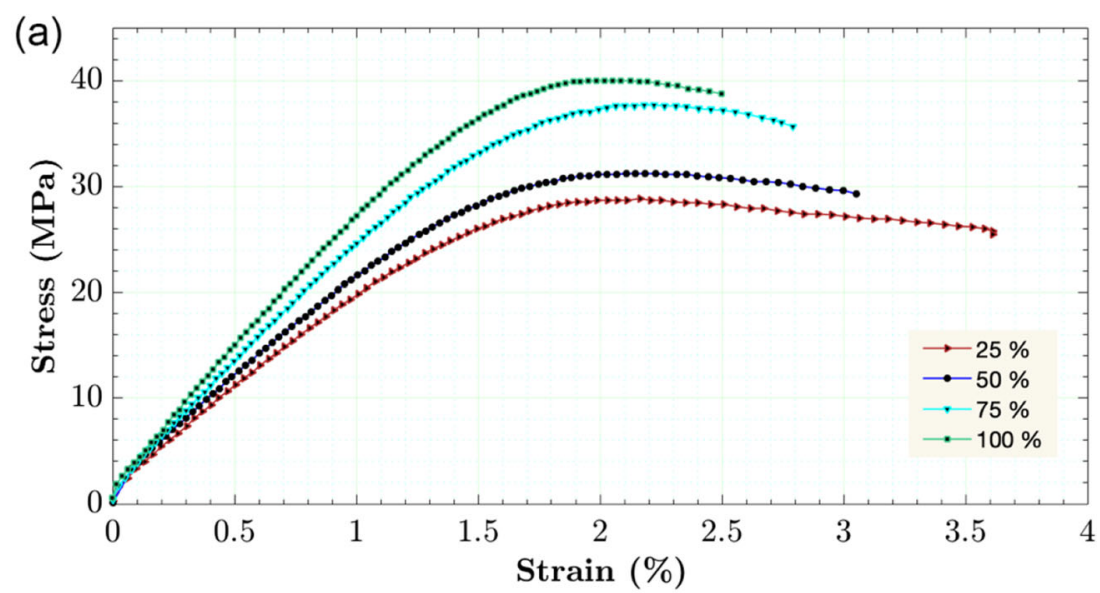

(b)

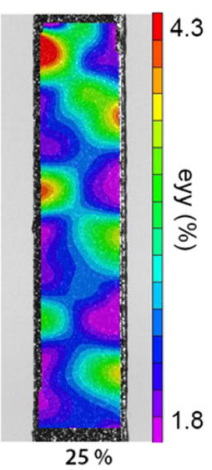

(c)

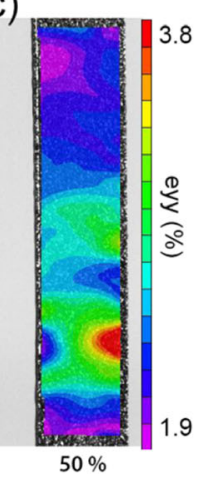

(d)

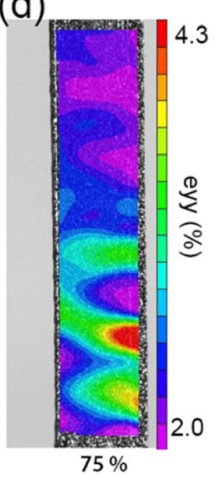

(e)

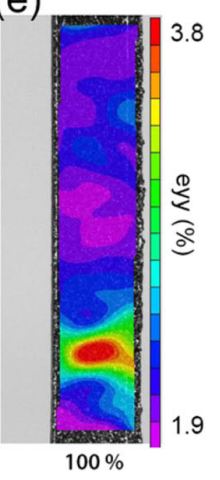

its fully dense counterpart should vary as the relative density squared so a power law fit with order 2 might be expected to give the best fit. However, the samples prepared here have a relatively dense shell surrounding the region of lower infill density so this is modified to the quadratic variation which shows the excellent fit in Fig. 8a.

Poisson's ratio also increases very slightly with infill density $\left(\nu_{m}=0.31\right.$ for $25 \%$ and $\nu_{m}=0.33$ for $\left.100 \%\right)$. The specimens with $25 \%$ infill density have lowest performance, with reduction of $23.6 \%$ tensile strength and $25.45 \%$ Young's modulus, compared with $100 \%$ infill density. In short, it is

(a)

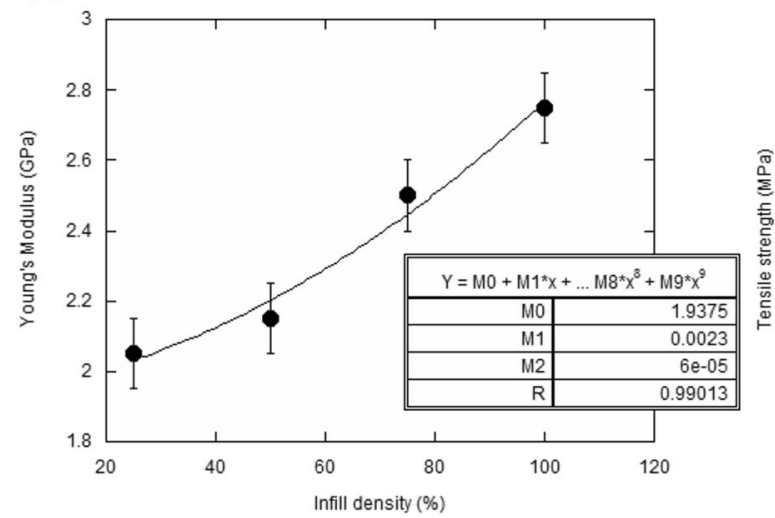

best to select the highest infill density 3D FFF parts for optimum mechanical response but this can increase build time and cost so a compromise may be necessary. The effect of infill density on ductility is less significant but it is worth noting that the ductility decreases as the infill density increases. The tensile strain at fracture for $25 \%$ infill density was $\sim \varepsilon_{f}=3.4 \%$ and it decreased to $\varepsilon_{f} \sim 2.25 \%$ at $100 \%$ density.

The strain field obtained by the DIC technique under tensile loading at four different infill densities is illustrated in Fig. 7. Figure $7 \mathrm{~b}-\mathrm{e}$ show DIC results in terms of longitudinal strain field plots $\varepsilon_{y y}$ (in the loading direction) near to the final

(b)

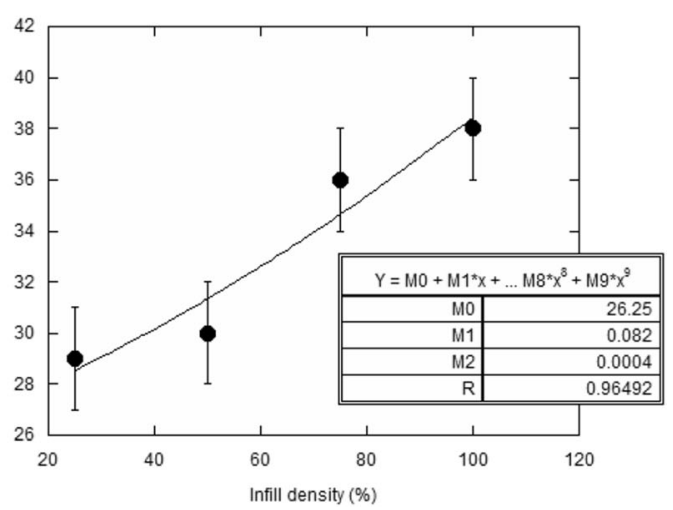

Fig. 8 Variation of a Young's modulus and $\mathbf{b}$ tensile strength with infill density 
(a)

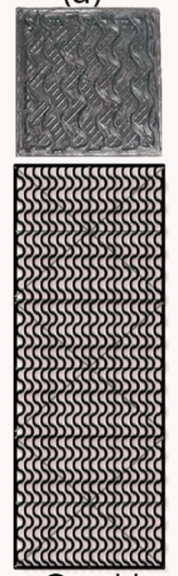

Gyroid (b)

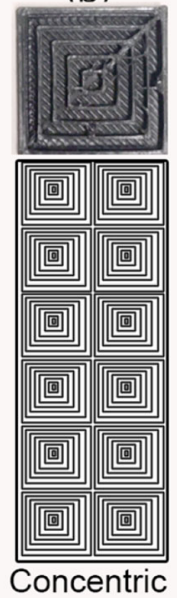

(c)

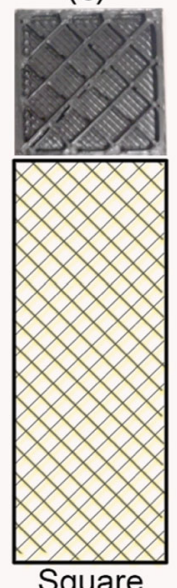

Square (d)

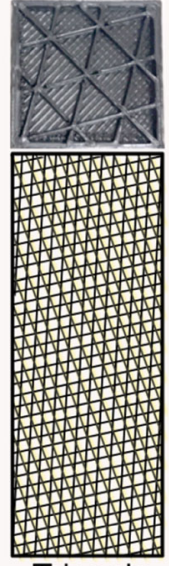

Triangle

Fig. 9 Schematic of different 3D printing infill patterns a gyroid, b concentric, $\mathbf{c}$ square grid and $\mathbf{d}$ triangle

failure (about 95\% of failure load). All specimens failed within the gauge length as shown in Fig. 7. In almost all infill densities, the results show very high localised strain at the edge of the sample. For 25\% infill density, lots of regions of high strain concentration were observed at the edge of the sample ultimately leading to fracture. A very high local strain value $\left(\varepsilon_{y y}=4.3 \%\right)$ was observed in one of these locations

(Fig. 7b). In case of 50\% infill density, there were a smaller number of localised strain concentrations and these penetrated deeper into the middle of the sample. A similar pattern was observed in the case of the $75 \%$ infill density. At $100 \%$ infill density, the single large region of localised strain concentration was in the middle of the sample. The comparison shows that reducing the number of localised strain concentrations markedly lowers strain at failure when the infill densities increase which confirms the substantial effect of infill densities on mechanical properties of 3D FFF parts.

\subsubsection{Effect of infill pattern on mechanical properties}

The prior research on the 3D FFF parts has mainly focused on a linear infill pattern, with the main object to find the effect of infill material types and orientations, not on different build patterns $[52,59]$. In this study, we compared four different patterns (i.e. gyroid, concentric, triangle and square (Fig. 9)) printed at 50\% infill density. Figure 10 illustrates stress-strain curves for these four patterns and their tensile properties are provided in Table 6.

The stress-strain curves illustrated in Fig. 10 show that the different patterns have a minor effect on mechanical properties of the sample in comparison to build orientation and infill density. For the gyroid, the tensile strength and elastic modu-
Fig. 10 a Tensile stress-strain curves for different infill pattern of 3D FFF-printed PLA measured by the DIC method (the infill density of 50\%); the DIC strain distribution map along the tensile specimens of different patterns of b gyroid, c concentric, $\mathbf{d}$ triangle and e square grid

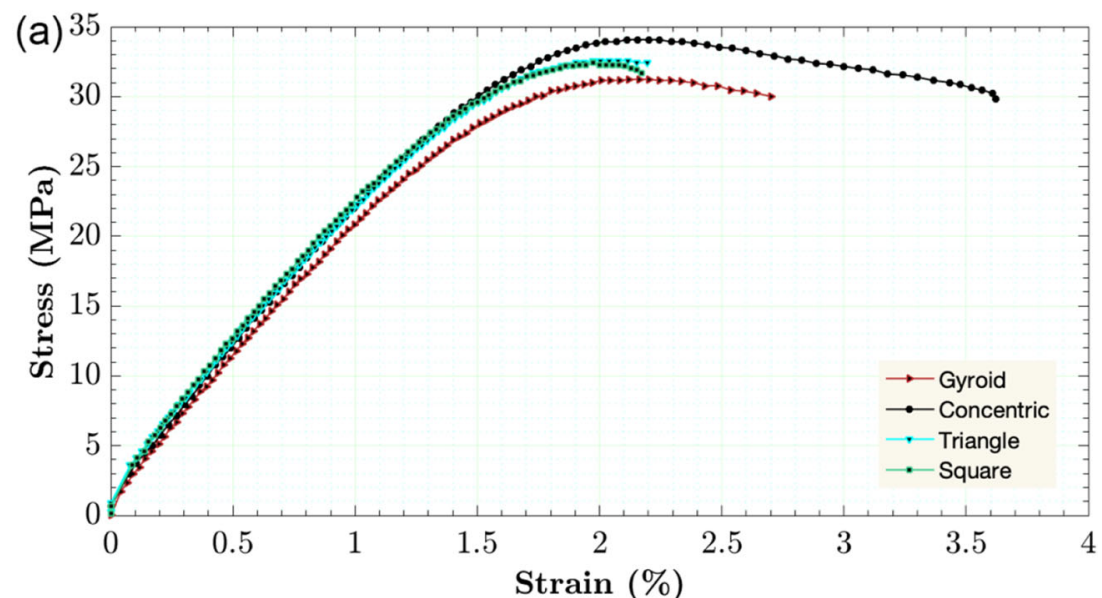

(b)

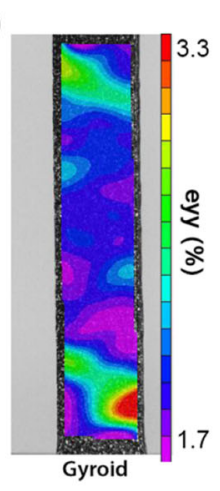

(c)

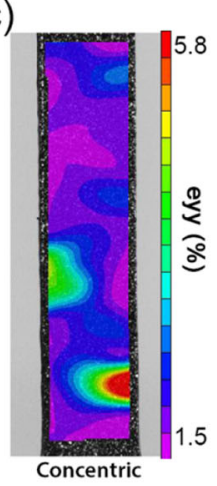

(d)

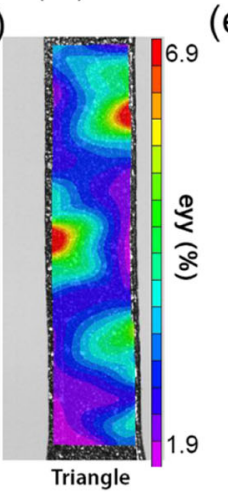

(e)

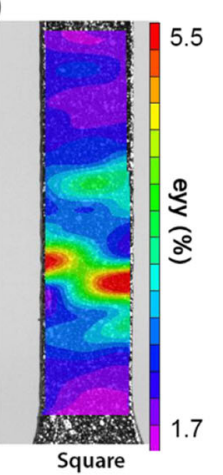


Table 6 Tensile properties of 3D FFF-printed PLA as a function of infill pattern

\begin{tabular}{llllllc}
\hline Infill pattern & $\begin{array}{l}\text { Ultimate tensile } \\
\text { strength (MPa) }\end{array}$ & $\begin{array}{l}\text { Difference to } \\
\text { filament }\end{array}$ & $\begin{array}{l}\text { Ultimate tensile } \\
\text { strain (\%) }\end{array}$ & Poisson's ratio & $\begin{array}{l}\text { Elastic } \\
\text { modulus (GPa) }\end{array}$ & \begin{tabular}{c} 
Failure strain (\%) \\
\hline $50 \%$ concentric
\end{tabular} \\
\hline $31 \pm 1$ & -39 & $2.15 \pm 0.05$ & $0.32 \pm 0.01$ & $2.2 \pm 0.05$ & $3.5 \pm 0.1$ \\
$50 \%$ gyroid & $30 \pm 1$ & -41 & $2.12 \pm 0.03$ & $0.31 \pm 0.01$ & $2.2 \pm 0.05$ & $2.75 \pm 0.3$ \\
$50 \%$ square & $31 \pm 1$ & -39 & $2.1 \pm 0.05$ & $0.32 \pm 0.01$ & $2.28 \pm 0.04$ & $2.35 \pm 0.15$ \\
$50 \%$ triangle & $31 \pm 1$ & -39 & $2 \pm 0.05$ & $0.32 \pm 0.02$ & $2.15 \pm 0.05$ & $2.33 \pm 0.05$ \\
\hline
\end{tabular}

lus were lowest, while the tensile strength and elastic modulus were almost identical for concentric, triangle and square patterns (Table 6). In terms of Poisson's ratio, the variation in values was negligible for all four different infill pattern cases. The tensile strain at fracture in the case of concentric pattern was $27 \%$ and $48.9 \%$ larger in comparison to gyroid and square infill patterns respectively. Thus, the variation in tensile properties with respect to infill pattern choice was small; however, the concentric pattern had a slightly better mechanical response in all measurements here.

The strain fields obtained by the DIC technique for the four different infill patterns under tensile loading are illustrated in Fig. 10. Figure 10b-e shows DIC results obtained in terms of longitudinal strain field plots $\varepsilon_{y y}$ (loading direction) near to failure (about $95 \%$ of failure) load. All specimens failed within the gauge length. All infill patterns show a very high localised strain at the edge of the sample. For the square pattern, a high strain concentration was observed at the edge just near the grip and led to fracture; the localised strain value at this point was $\varepsilon_{y y}=3.3 \%$ (Fig. $10 \mathrm{e}$ ). For the triangle pattern, a single high local strain concentration was also observed at the edge just near to the grip and this caused fracture the same as for the square pattern; a higher localised strain value $\left(\varepsilon_{y y}=\right.$ $5.8 \%$ ) was observed (Fig. 10d). In case of concentric and gyroid patterns, very high localised strains occurred at several positions only one of which led to fracture; the peak strains in these cases were 6-7\% suggesting that these infill designs can accommodate more strain in the material.
Fig. 11 a Shear stress-strain curves for different build orientation of 3D FFF-printed PLA measured by the DIC method (parallel fibres with the infill density of $100 \%)$; the DIC strain distribution map along the shear specimens of $\mathbf{b} 0^{\circ}$ on-edge orientation, $\mathbf{c} 0^{\circ}$ flat orientation, $\mathbf{d}$ $45^{\circ}$ flat orientation and e $50 \%$ upright orientation

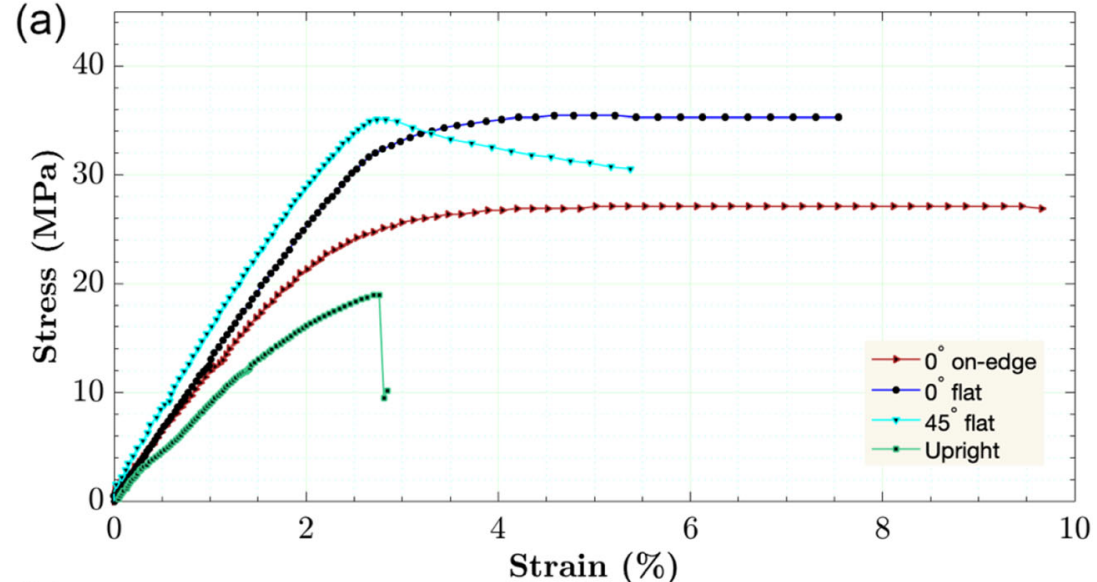

(b)

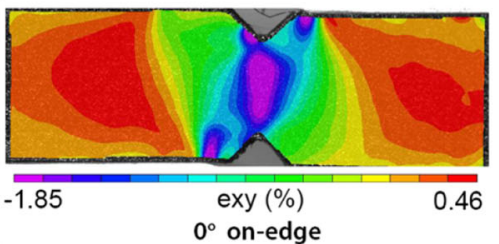

(d)

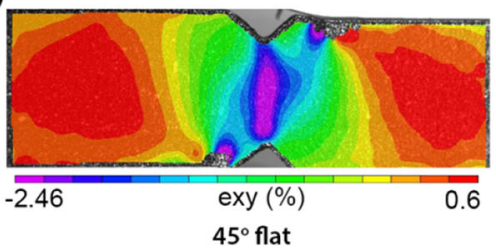

(c)

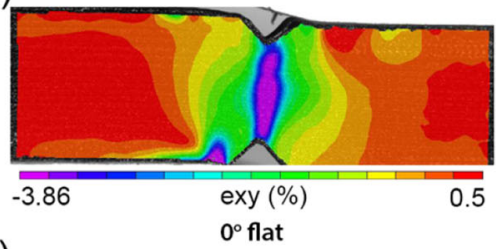

(e)

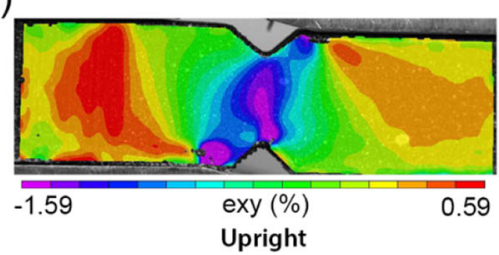


Table 7 Shear properties of 3D FFF-printed PLA as a function of build orientation

\begin{tabular}{lllll}
\hline Specimen & Shear strength (MPa) & Yield strength (MPa) & $\begin{array}{l}\text { Shear modulus } \\
(\mathrm{GPa})\end{array}$ & Failure shear strain (\%) \\
\hline $0^{\circ}$ on-edge & $27 \pm 0.6$ & $23 \pm 0.6$ & $1.21 \pm 0.03$ & $9.6 \pm 0.3$ \\
$0^{\circ}$ flat & $35 \pm 0.5$ & $30 \pm 0.5$ & $1.27 \pm \pm 0.05$ & $7.5 \pm 0.2$ \\
$45^{\circ}$ flat & $36 \pm 0.3$ & $33 \pm 0.3$ & $1.55 \pm 0.08$ & $5.5 \pm 0.4$ \\
Upright & $18 \pm 0.5$ & $17.5 \pm 0.5$ & $0.95 \pm 0.06$ & $2.1 \pm 0.3$ \\
\hline
\end{tabular}

\subsection{Shear tests}

Figure 11 illustrates shear stress-strain curves for different build orientations of $0^{\circ}$ on-edge, $0^{\circ}$ flat, $45^{\circ}$ flat and upright. There are significant variations in shear strength and shear modulus as a function of build orientation as presented in Table 7. The shear stress-strain curves reveal the same trends as seen in tensile results in that the PLA exhibits remarkable anisotropy.

The $45^{\circ}$ flat orientation shows the highest values for maximum shear strength and shear modulus which were about $\tau=$ $36 \mathrm{MPa}$ and $G_{y x}=1.55 \mathrm{GPa}$ respectively, while the upright orientation resulted in the lowest values. The shear strength and shear modulus were about $\tau=18 \mathrm{MPa}$ and $G_{y x}=0.95 \mathrm{GPa}$ respectively for the upright orientation, which is about $50 \%$ and $38.7 \%$ less than the $45^{\circ}$ flat orientation. The $0^{\circ}$ on-edge orientation depicted lower shear strength and shear modulus ( $\tau=27 \mathrm{MPa}$ and $G_{y x}=1.21 \mathrm{GPa}$ respectively) as compared to the $45^{\circ}$ flat orientation. In the case of the $0^{\circ}$ flat, the shear strength and shear modulus were about $\tau=35 \mathrm{MPa}$ and $G_{y x}=$ 1.27 GPa respectively. The shear modulus appears isotropic as a function of build orientation, unlike the results seen in tensile testing. However, the upright specimens featured the lowest values (Table 7), which indicates weak adhesion between the deposited layers of PLA. These results have confirmed the results of previous studies [22].
The strain fields obtained by DIC under shear loading at four different build orientations are illustrated in Fig. 11. Figure $11 \mathrm{~b}-\mathrm{e}$ show DIC results in terms of the shear strain, $\gamma_{x y}$, distribution just before failure (at about $95 \%$ of failure load) for the four different build orientations. It is seen that all specimens failed within the gauge length. In all the four cases, the DIC results show the specimens appeared to delaminate along the notched area and very high localised strains occur near to the notches in the Iosipescu specimen as expected. Noticeably, the build orientations appeared to have less effect on shear modulus as only the upright specimen was significantly different from the other orientations. For the $0^{\circ}$ on-edge specimen, the localised shear strain maximum was $\sim \gamma_{x y}=0.4 \%$, whereas $\gamma_{x y}=0.5 \%$ for the $0^{\circ}$ flat specimen. Comparing the $45^{\circ}$ flat and upright specimens, the maximum localised shear strain was almost identical. The results show a good agreement with tensile testing. Thus, it is reasonable to conclude that the 3D FFF part on-edge specimens showed the optimal mechanical performance in terms of strength, modulus and ductility in both tensile and shear testing.

\subsection{Fractography analysis of tensile failure}

The breakage occurred within the gauge length for all the specimens tested. Figure 12 shows SEM images of the fractured surface of tensile specimens of $0^{\circ}$ on-edge, $0^{\circ}$ flat, $45^{\circ}$,

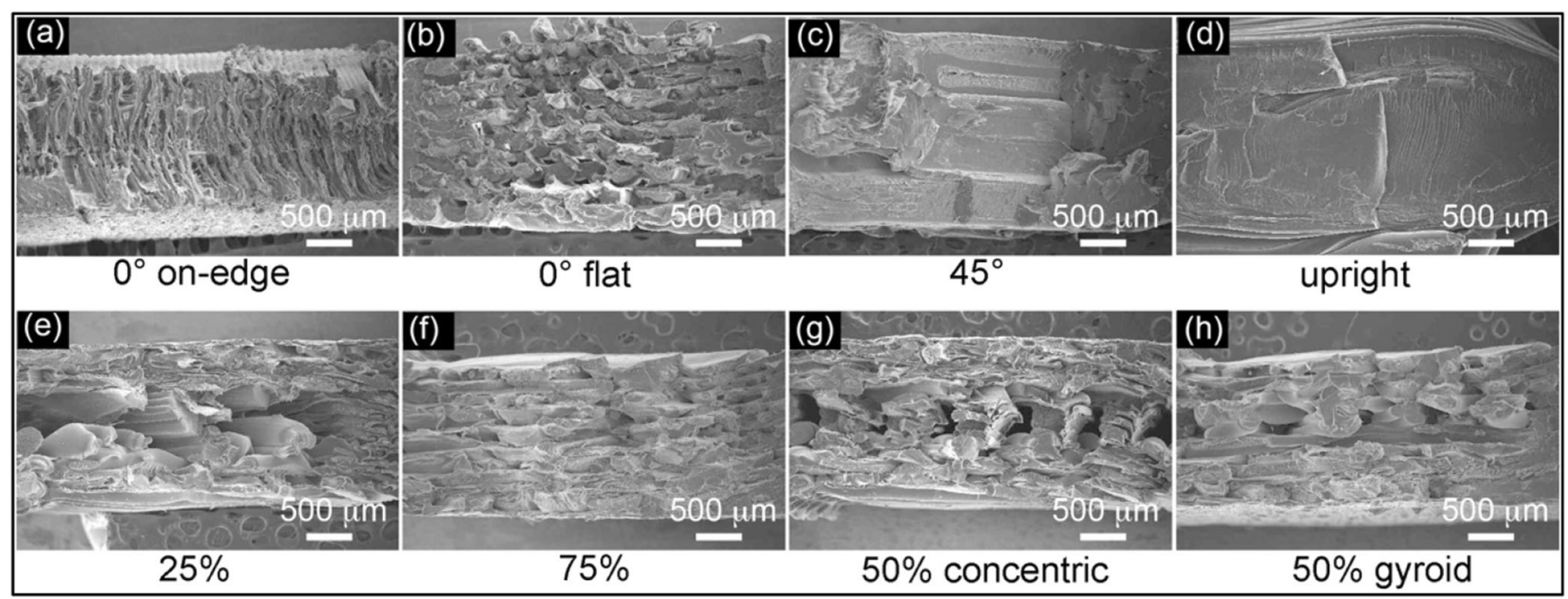

Fig. 12 SEM images illustrating details of the fracture surfaces of $\mathbf{a} 0^{\circ}$ on-edge orientation, $\mathbf{b} 0^{\circ}$ flat orientation, $\mathbf{c} 45^{\circ}$ orientation, $\mathbf{d}$ upright orientation, $\mathbf{e}$ $25 \%$ infill density, $\mathbf{f} 75 \%$ infill density, $\mathbf{g} 50 \%$ concentric pattern and $\mathbf{h} 50 \%$ gyroid pattern 
upright, $25 \%$ infill density, $75 \%$ infill density, $50 \%$ concentric pattern and $50 \%$ gyroid pattern. Comparison of the fracture morphology shows the failure mode changes as a function of build orientation. Failure from on-edge to upright orientation changes from ductile to brittle; the transition in behaviour from ductile to brittle fracture is mainly due to the layer deposition direction. In $0^{\circ}$ on-edge orientation, the layer deposition direction was perpendicular to the specimen axis and the load was applied parallel to the layers, which is mainly associated with trans-layer failure and therefore shows ductile fracture with significant plastic deformation (see stress-strain curve, illustrated in Fig. 5). As the build angle increases, the specimens display an intermediate brittle-ductile fracture behaviour. Noticeably, when the build orientation angles increase $\left(\geq 45^{\circ}\right)$, the specimen demonstrates the transition to brittle failure, with little plastic deformation. The upright orientation fails by brittle fracture due to inter-layer fusion bond failure as the load is applied perpendicular to their layers; the stressstrain curve exhibits linear behaviour followed by sudden failure.

Figure $12 \mathrm{e}, \mathrm{f}$ show the SEM images of the tensile fracture surface for $25 \%$ and $75 \%$ infill densities, whereas Fig. $12 \mathrm{~g}, \mathrm{~h}$ show the 50\% concentric and 50\% gyroid pattern fracture surfaces respectively. The $50 \%$ infill density displays a mixed brittle-ductile behaviour. For the $25 \%$ infill density, the empty space between the layer interfaces is greater as compared to $75 \%$ infill density, and there is more plastic deformation in the solid regions at lower infill density. Changing the infill pattern does not significantly change the plastic response as seen in the stress-strain curve.

\section{Conclusions}

In this work, the effect of build orientation, infill density and infill pattern on the mechanical properties of 3D-printed polylactic acid (PLA) specimens was investigated with the aid of digital image correlation (DIC). Samples according to the ASTM standard D-638 for tensile (type IV) and D-5379 for shear geometry were created using fused filament fabrication (FFF) 3D printing. Digital image correlation (DIC) was employed to get full-field surface-strain measurements. The mechanical response was shown to significantly vary as a function of process parameters, especially the build orientation. Anisotropy was found when comparing the on-edge, flat and upright orientations of 3D FFF-printed PLA specimens. For on-edge samples typical values, the tensile strength and Young's modulus were found to be $55 \mathrm{MPa}$ and $3.5 \mathrm{GPa}$, and for the upright orientation, they were $5 \mathrm{MPa}$ and $2 \mathrm{GPa}$ respectively. Similar anisotropy was observed in shear tests. With increasing infill density, the tensile strength and Young's modulus increase in a quadratic fashion. When the filament deposition direction aligns with loading direction, the mechanical properties of the test pieces are almost identical to those of the individual filaments. When the loading axis is at an angle to the filament deposition direction, lower strength and stiffness values were produced; the fusion between deposited filaments is not perfect leading to defects between them which affect mechanical properties. This is true for both build orientation and raster direction. The experimental results were compared to an analytical constitutive model based on laminate theory predictions. Identical trends were observed with the predictions greater than the measured results due to the defects introduced in the printing process and tensile loading on the interface between deposited filament lines. For different infill patterns, the mechanical response did not vary significantly.

Acknowledgments The authors would like to thank Neville Dickmann for help with testing and the EPSRC for the provision of funding through the North East Centre for Energy Materials (NECEM).

Open Access This article is licensed under a Creative Commons Attribution 4.0 International License, which permits use, sharing, adaptation, distribution and reproduction in any medium or format, as long as you give appropriate credit to the original author(s) and the source, provide a link to the Creative Commons licence, and indicate if changes were made. The images or other third party material in this article are included in the article's Creative Commons licence, unless indicated otherwise in a credit line to the material. If material is not included in the article's Creative Commons licence and your intended use is not permitted by statutory regulation or exceeds the permitted use, you will need to obtain permission directly from the copyright holder. To view a copy of this licence, visit http://creativecommons.org/licenses/by/4.0/.

\section{References}

1. Murr LE (2016) Frontiers of 3D printing/additive manufacturing: from human organs to aircraft fabrication. J Mater Sci Technol 32: 987-995. https://doi.org/10.1016/j.jmst.2016.08.011

2. Kobryn P, Ontko N, Perkins L, and Tiley J (2006) Additive manufacturing of aerospace alloys for aircraft structures. in, Air Force Research Lab Wright-Patterson AFB OH Materials and Manufacturing

3. Labonnote N, Ronnquist A, Manum B, Ruther P (2016) Additive construction: state-of-the-art, challenges and opportunities. Autom Constr 72:347-366. https://doi.org/10.1016/j.autcon.2016.08.026

4. Ghaffar SH, Corker J, Fan MZ (2018) Additive manufacturing technology and its implementation in construction as an ecoinnovative solution. Autom Constr 93:1-11. https://doi.org/10. 1016/j.autcon.2018.05.005

5. Ghaffar S, Mullett $P$ (2018) Commentary: $3 D$ printing set to transform the construction industry. P I Civil Eng-Str B 171:737-738. https://doi.org/10.1680/jstbu.18.00136

6. Paolini A, Kollmannsberger S, Rank E (2019) Additive manufacturing in construction: a review on processes, applications, and digital planning methods. Addit Manuf 30:100894. ARTN 100894. https://doi.org/10.1016/j.addma.2019.100894

7. Chen RK, Y-a J, Wensman J, Shih A (2016) Additive manufacturing of custom orthoses and prostheses - a review. Addit Manuf 12: $77-89$ 
8. Knowlton S, Yenilmez B, Tasoglu S (2016) Towards single-step biofabrication of organs on a chip via $3 \mathrm{D}$ printing. Trends Biotechnol 34:685-688. https://doi.org/10.1016/j.tibtech.2016.06. 005

9. Ji S, Guvendiren M (2017) Recent advances in bioink design for 3D bioprinting of tissues and organs. Front Bioeng Biotechnol 5:23. https://doi.org/10.3389/fbioe.2017.00023

10. Lepowsky E, Tasoglu S (2018) 3D printing for drug manufacturing: a perspective on the future of pharmaceuticals. Int J Bioprint 4: UNSP 119. https://doi.org/10.18063/IJB.v4i1.119

11. Won J, DeLaurentis K, and Mavroidis C (2000) Rapid prototyping of robotic systems. in: Proceedings 2000 ICRA. Millennium Conference. IEEE International Conference on Robotics and Automation. Symposia Proceedings (Cat. No. 00CH37065), IEEE, pp. 3077-3082

12. Tse W and Chen Y (1997) A robotic system for rapid prototyping. in: Proceedings of International Conference on Robotics and Automation, IEEE, pp. 1815-1820

13. Ahn SH, Baek C, Lee S, Ahn IS (2003) Anisotropic tensile failure model of rapid prototyping parts-fused deposition modeling (FDM). Int J Mod Phys B 17:1510-1516. https://doi.org/10.1142/ S0217979203019241

14. Sood AK, Ohdar RK, Mahapatra SS (2010) Parametric appraisal of mechanical property of fused deposition modelling processed parts. Mater Des 31:287-295. https://doi.org/10.1016/j.matdes.2009.06. 016

15. Bagsik A, Schoppner V, and Klemp E (2010) FDM part quality manufactured with Ultem* 9085. in: 14th international scientific conference on polymeric materials, pp. 307-315

16. Farzadi A, Solati-Hashjin M, Asadi-Eydivand M, Osman NAA (2014) Effect of layer thickness and printing orientation on mechanical properties and dimensional accuracy of $3 \mathrm{D}$ printed porous samples for bone tissue engineering. PLoS One 9:e108252. https://doi. org/10.1371/journal.pone. 0108252

17. Lanzotti A, Grasso M, Staiano G, Martorelli M (2015) The impact of process parameters on mechanical properties of parts fabricated in PLA with an open-source 3-D printer. Rapid Prototyp J 21:604 617. https://doi.org/10.1108/RPJ-09-2014-0135

18. Rezayat H, Zhou W, Siriruk A, Penumadu D, Babu S (2015) Structure-mechanical property relationship in fused deposition modelling. Mater Sci Technol 31:895-903. https://doi.org/10. 1179/1743284715Y.0000000010

19. Wu W, Geng P, Li G, Zhao D, Zhang H, Zhao J (2015) Influence of layer thickness and raster angle on the mechanical properties of 3Dprinted PEEK and a comparative mechanical study between PEEK and ABS. Materials 8:5834-5846. https://doi.org/10.3390/ ma8095271

20. Casavola C, Cazzato A, Moramarco V, Pappalettere C (2016) Orthotropic mechanical properties of fused deposition modelling parts described by classical laminate theory. Mater Des 90:453458. https://doi.org/10.1016/j.matdes.2015.11.009

21. Rankouhi B, Javadpour S, Delfanian F, Letcher T (2016) Failure analysis and mechanical characterization of $3 \mathrm{D}$ printed $\mathrm{ABS}$ with respect to layer thickness and orientation. J Fail Anal Prev 16:467481. https://doi.org/10.1007/s11668-016-0113-2

22. Cantrell Jason T, Rohde S, Damiani D, Gurnani R, DiSandro L, Anton J, Young A, Jerez A, Steinbach D, Kroese C, Ifju Peter G (2017) Experimental characterization of the mechanical properties of 3D-printed ABS and polycarbonate parts. Rapid Prototyp J 23: 811-824. https://doi.org/10.1108/RPJ-03-2016-0042

23. Ning F, Cong W, Hu Y, Wang H (2017) Additive manufacturing of carbon fiber-reinforced plastic composites using fused deposition modeling: effects of process parameters on tensile properties. J Compos Mater 51:451-462

24. Zaldivar R, Witkin D, McLouth T, Patel D, Schmitt K, Nokes J (2017) Influence of processing and orientation print effects on the mechanical and thermal behavior of 3D-printed ULTEM® 9085 material. Addit Manuf 13:71-80. https://doi.org/10.1016/j.addma. 2016.11.007

25. Vaezi M, Chua CK (2011) Effects of layer thickness and binder saturation level parameters on 3D printing process. Int J Adv Manuf Technol 53:275-284. https://doi.org/10.1007/s00170-010-2821-1

26. Rodríguez JF, Thomas JP, Renaud JE (2001) Mechanical behavior of acrylonitrile butadiene styrene (ABS) fused deposition materials. Experimental Investigation, Rapid Prototyp J 7:148-158. https:// doi.org/10.1108/13552540110395547

27. Ahn SH, Montero M, Odell D, Roundy S, Wright Paul K (2002) Anisotropic material properties of fused deposition modeling ABS. Rapid Prototyp J 8:248-257. https://doi.org/10.1108/ 13552540210441166

28. Zou R, Xia Y, Liu S, Hu P, Hou W, Hu Q, Shan C (2016) Isotropic and anisotropic elasticity and yielding of $3 \mathrm{D}$ printed material. Compos Part B 99:506-513. https://doi.org/10.1016/j. compositesb.2016.06.009

29. Ziemian C, Sharma M, Ziemian S (2012) Anisotropic mechanical properties of ABS parts fabricated by fused deposition modelling. Mech Eng. https://doi.org/10.5772/34233

30. Onwubolu GC and F Rayegani (2014) Characterization and optimization of mechanical properties of ABS parts manufactured by the fused deposition modelling process. Int J Manuf Eng, 2014. https://doi.org/10.1155/2014/598531

31. Durgun I, Ertan R (2014) Experimental investigation of FDM process for improvement of mechanical properties and production cost. Rapid Prototyp J 20:228-235. https://doi.org/10.1108/RPJ-102012-0091

32. Hill N, Haghi M (2014) Deposition direction-dependent failure criteria for fused deposition modeling polycarbonate. Rapid Prototyp J 20:221-227. https://doi.org/10.1108/RPJ-04-2013-0039

33. Chacón JM, Caminero MA, García-Plaza E, Núñez PJ (2017) Additive manufacturing of PLA structures using fused deposition modelling: effect of process parameters on mechanical properties and their optimal selection. Mater Des 124:143-157. https://doi. org/10.1016/j.matdes.2017.03.065

34. Chacon JM, Caminero MA, Garcia-Plaza E, Nunez PJ (2017) Additive manufacturing of PLA structures using fused deposition modelling: effect of process parameters on mechanical properties and their optimal selection. Mater Des 124:143-157. https://doi. org/10.1016/j.matdes.2017.03.065

35. Somireddy M, Czekanski A, Singh CV (2018) Development of constitutive material model of 3D printed structure via FDM. Mater Today Commun 15:143-152

36. Lee CS, Kim SG, Kim HJ, Ahn SH (2007) Measurement of anisotropic compressive strength of rapid prototyping parts. J Mater Process Technol 187-188:627-630. https://doi.org/10.1016/j. jmatprotec.2006.11.095

37. Panda SK, Padhee S, Anoop Kumar S, Mahapatra SS (2009) Optimization of fused deposition modelling (FDM) process parameters using bacterial foraging technique. Intell Inf Manag 1:89-97. https://doi.org/10.4236/iim.2009.12014

38. Zhang JW and AH Peng,(2012) Process-parameter optimization for fused deposition modeling based on Taguchi method. In: Advanced Materials Research, Trans Tech Publ, pp. 444-447

39. Rodríguez JF, JP Thomas, and JE Renaud (2003) Design of fuseddeposition ABS components for stiffness and strength. J Mech Des, 125:545-551

40. Ulu E, Korkmaz E, Yay K, Ozdoganlar OB, Kara LB (2015) Enhancing the structural performance of additively manufactured objects through build orientation optimization. J Mech Des 137: 111410

41. Lee BH, Abdullah J, Khan ZA (2005) Optimization of rapid prototyping parameters for production of flexible ABS object. J Mater Process Technol 169:54-61 
42. Letcher T, B Rankouhi, and S Javadpour,(2015) Experimental study of mechanical properties of additively manufactured ABS plastic as a function of layer parameters. in: ASME 2015 International Mechanical Engineering Congress and Exposition, American Society of Mechanical Engineers, pp. V02AT02A018V002AT002A018

43. Ahn S-H, Montero M, Odell D, Roundy S, Wright PK (2002) Anisotropic material properties of fused deposition modeling ABS. Rapid Prototyp J 8:248-257

44. Hao W, Liu Y, Wang T, Guo G, Chen H, Fang D (2019) Failure analysis of 3D printed glass fiber/PA12 composite lattice structures using DIC. Compos Struct 225:111192. https://doi.org/10.1016/j. compstruct.2019.111192

45. Pyl L, Kalteremidou K-A, Van Hemelrijck D (2019) Exploration of the design freedom of $3 \mathrm{D}$ printed continuous fibre-reinforced polymers in open-hole tensile strength tests. Compos Sci Technol 171: 135-151. https://doi.org/10.1016/j.compscitech.2018.12.021

46. Reddy JN (2003) Mechanics of laminated composite plates and shells: theory and analysis. CRC press

47. ASTM D638-14 (2015) Standard test method for tensile properties of. Plastics, ASTM International International, West Conshohocken, PA

48. ASTM D (2005) 5379/D 5379M: standard test method for shear properties of composites materials by the v-notched beam method, ASTM International, West Conshohocken, PA

49. Crawford RJ, Martin PJ (2020) Plastics engineering. ButterworthHeinemann

50. Sutton MA, Mingqi C, Peters WH, Chao YJ, McNeill SR (1986) Application of an optimized digital correlation method to planar deformation analysis. Image Vis Comput 4:143-150. https://doi. org/10.1016/0262-8856(86)90057-0

51. Hild F, Roux S (2006) Digital image correlation: from displacement measurement to identification of elastic properties-a review. Strain 42:69-80. https://doi.org/10.1111/j.1475-1305.2006.00258.x

52. Dizon JRC, Espera AH, Chen Q, Advincula RC (2018) Mechanical characterization of 3D-printed polymers. Addit Manuf 20:44-67. https://oi.org/10.1016/j.addma.2017.12.002
53. Letcher T and Waytashek M (2014) Material Property Testing of 3D-Printed Specimen in PLA on an Entry-Level 3D Printer. in: ASME 2014 International Mechanical Engineering Congress and Exposition

54. Domingo-Espin M, Puigoriol-Forcada JM, Garcia-Granada A-A, Llumà J, Borros S, Reyes G (2015) Mechanical property characterization and simulation of fused deposition modeling polycarbonate parts. Mater Des 83:670-677. https://doi.org/10.1016/j.matdes. 2015.06.074

55. Torrado AR, Roberson DA (2016) Failure analysis and anisotropy evaluation of 3D-printed tensile test specimens of different geometries and print raster patterns. J Fail Anal Prev 16:154-164. https:// doi.org/10.1007/s11668-016-0067-4

56. Akhoundi B, Behravesh AH (2019) Effect of filling pattern on the tensile and flexural mechanical properties of FDM 3D printed products. Exp Mech 59:883-897. https://doi.org/10.1007/s11340-01800467-y

57. Dave HK, Patadiya NH, Prajapati AR, and Rajpurohit SR (2019) Effect of infill pattern and infill density at varying part orientation on tensile properties of fused deposition modeling-printed poly-lactic acid part. Proceedings of the Institution of Mechanical Engineers, Part C: Journal of Mechanical Engineering Science, 0954406219856383. https://doi.org/10.1177/0954406219856383

58. Wang S, Ma Y, Deng Z, Zhang S, Cai J (2020) Effects of fused deposition modeling process parameters on tensile, dynamic mechanical properties of 3D printed polylactic acid materials. Polym Test 86:106483. https://doi.org/10.1016/j.polymertesting.2020. 106483

59. Song Y, Li Y, Song W, Yee K, Lee KY, Tagarielli VL (2017) Measurements of the mechanical response of unidirectional 3Dprinted PLA. Mater Des 123:154-164. https://doi.org/10.1016/j. matdes.2017.03.051

Publisher's note Springer Nature remains neutral with regard to jurisdictional claims in published maps and institutional affiliations. 